\title{
Design and Implementation of Simulation System of Electronic Commerce
}

\author{
Song $\mathrm{CHI}$ \\ Liaoning Jidian Polytechnic North Gold and Jewelry Processing Sub-college, Liaoning Dandong, \\ 118009, China \\ email: Sch_1979@126.com
}

Keywords: Financial professionals; Practice teaching; Simulated trading; Aided teaching; Performance assessment

\begin{abstract}
The rapid development of modern financial economics puts forward higher requirements on the training of financial professionals. Not only require students to master a wealth of theoretical knowledge, but also require them have some ability in practical operation and innovation. However, nowadays the simulation trading software on the market focuses on a quick demonstration. It is difficult to combine with theoretical knowledge to make a rational analysis and judgment, which makes it impossible to form a securities operating system. To solve this problem, we designed a simulated trading system for teaching, which focused on how to combine theoretical knowledge taught in class with real trading system operations closely. Real trading environment, the timely review of theory and rational evaluation of co-operation as a whole is both beneficial to teaching, also is helpful to the students' flexible use of knowledge.
\end{abstract}

\section{Introduction}

With the rapid development of information technology, the financial industry has highly become e-enabled. Updates of the technology and network construction are accelerated. Advanced trading tools such as self-service banking, Internet banking, mobile banking, high-frequency trading, program trading have been rapidly promoted and applied in the financial industry. While under the influence of "Fat Finger of Everbright Securities", financial instruments in the market has been questioned, but from a long-term point of view, the financial industry will be more and more technical and networked. This represents the general trend, advanced financial instruments transactions such as online banking, high-frequency trading, program trading and so on, will be more and more extensive in the practical application. And these advanced financial instruments are exactly what our students can’t learn from book. Financial professionals have strong theoretical and practical characteristics, but current situation widely emphasis on theoretical teaching and ignore practical application. Financial curriculums of Chinese colleges and universities lagged far behind the actual demand of the financial industry.

The current curriculum system puts too much emphasis on macro-financial theory and less on the application of micro-finance curriculum. This requires university teachers' innovation on the design of teaching methods, to get rid of only attaching importance to the theory and ignoring practice as it was in the past. To teach students with both finance theoretical knowledge and the practical skills of operation is a widespread concern and an urgent problem in colleges and universities. In addition, the rapid development of modern science and technology, especially computer technology, on the one hand brings serious challenge to the traditional way of teaching ideas and methods. It also provides a convenience to strengthen the practice of teaching reform for colleges and universities.

\section{The main problem of teaching simulated trading software}

1. Existing software always put multi-focus on the "short order" teaching mode. Always focus on a quick simulation. It is difficult to make a rational and theoretical knowledge combined with 
analysis and judgment, thus unable to form a system of operational thinking. Once the software used in teaching beginners, it is inevitable that students will simply take cut corners. They will ignore the importance of a solid foundation of knowledge, so this is not suitable for teaching simulation software applications.

2. Existing software based on the assessment of their performance is too one-sided. Currently simulated trading's performance evaluation is generally based on assigned students' account balances. More profits will bring the students more scores. This evaluation has its own rationale, but is not able to fully reflect the students' knowledge and mastery. However, real investment is influenced by many factors. Changes of market price are affected by supply and demand. the relationship between supply and demand also influenced by macro and micro uncertain factors. In addition, speculative or investment behavior also affects the behavior of traders. Investors from different cultural backgrounds have different behaviors. And the behavior itself will affect the price. So, it is difficult to judge students account balance condition. A lot of uncertain factors will directly affect trading results.

3. Existing software can’t achieve synchronous teaching mode. Existing software focused on the demonstration. Teaching experiment simulated trading is part of the investment courses, teaching purpose is to enable students to better understand the experimental theoretical knowledge in practice, the flexible application of theoretical knowledge. For securities teaching, teachers and students can interact synchronization is very important, so that the teacher can identify problems and make timely reminder, but also conducive to the students aware of the problem in practice.

\section{Design of teaching simulated trading system}

Teaching simulated trading system is a teacher-student interaction in simulated trading system, the design process is as follows:

1. Selective registration function. Teacher and student's two-party login mode system is setted up. Teachers login in with their number and name, add more information including email and so on. Students login in with Student ID and name, add information including professional, class, mail and so on. Student can select the appropriate teacher, it just reflects the teaching mode of one teacher-many students.

2. Log in function. Before entering the online trading system, the customers have to log in firstly. The login screen is shown in Figure 1:

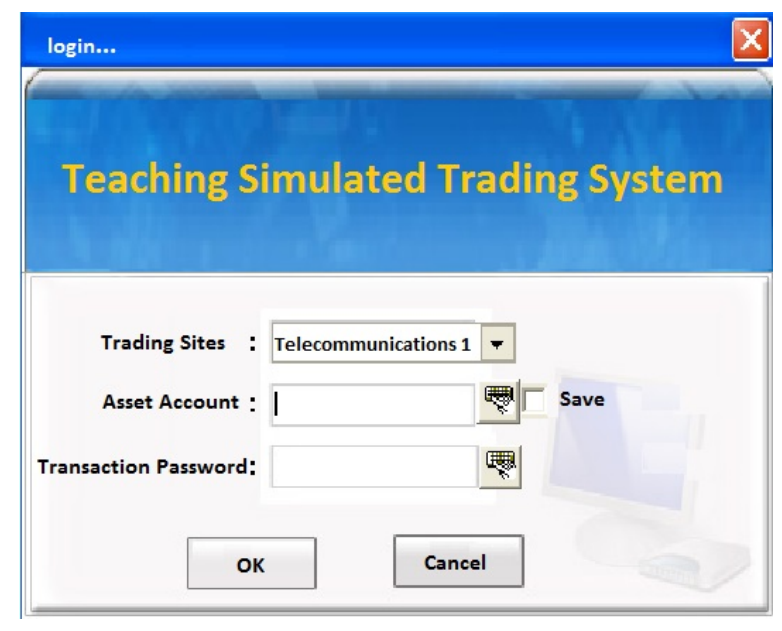

Fig.1. The login screen

3. Trading site maintenance function. Temporary replacement market trading address or the address or set up a proxy server, etc. Students can use the "Communication Settings" to enter the interface shown in Figure 3 for maintenance transaction sites: 


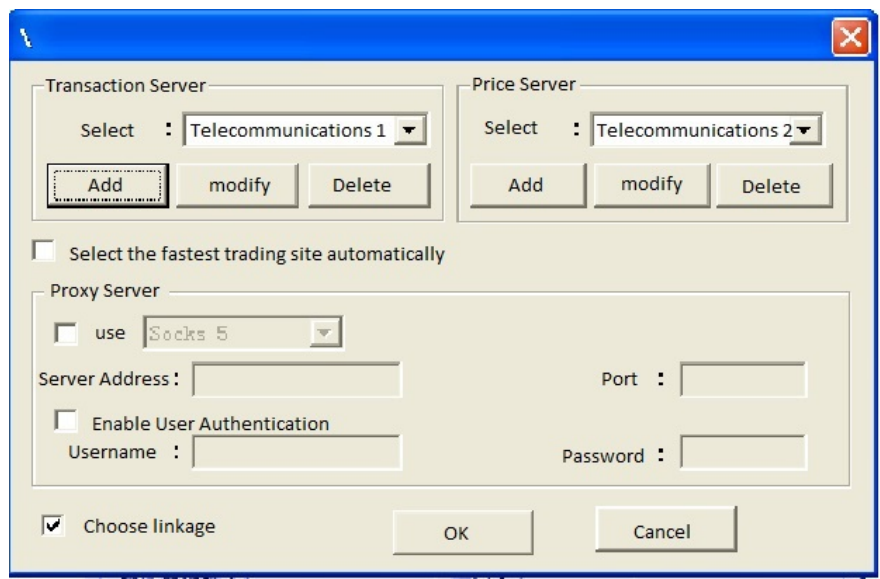

Fig.2. Trading site maintenance

4. Real-time transaction function. Like with others simulation software, the system also has a feature to synchronize the exchange of information. Students can check the corresponding transaction code in the form of dynamic, real-time analysis based on individual transactions.

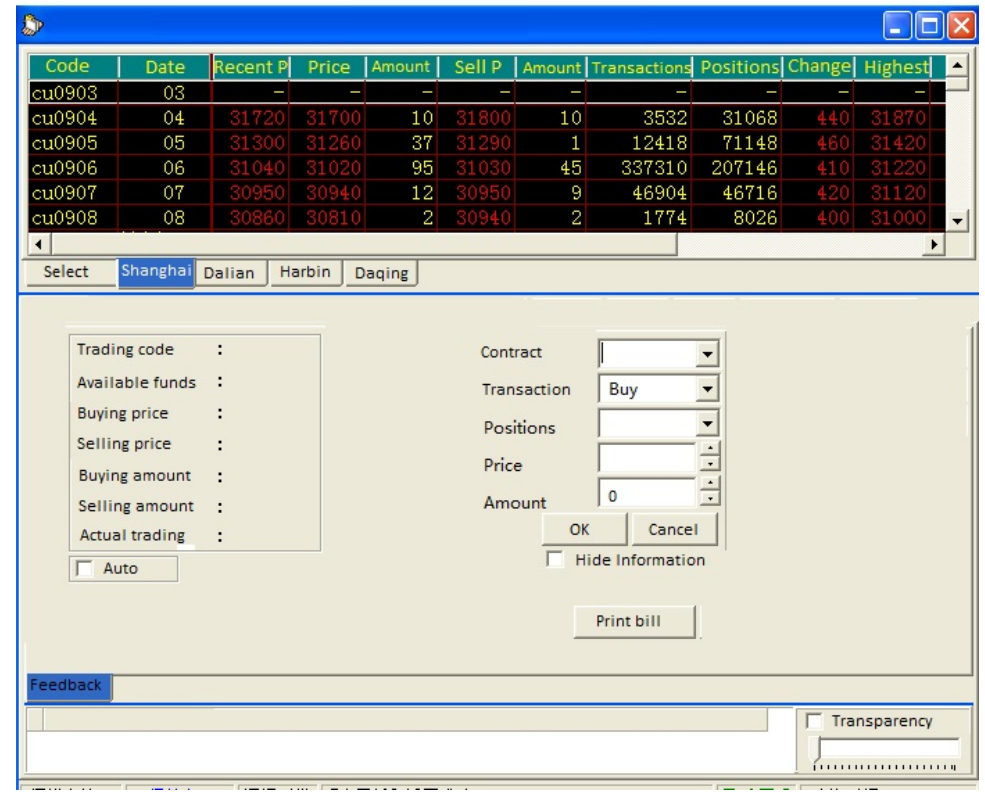

Fig.3. Real-time trading function interface

5. Reasonable evaluation function. The system implementation mechanism with automatic scoring machine manually score decided by teachers. Teachers need to check the students transactions combined trading experience to write scores of students in the Student Management Top menu bar, and then the system proportionally weighted data obtained scores of students' final grade teachers and students based on asset balances.

6. Consult function. System includes teachers ask students function. First, teachers can record the transaction by the students some time to observe the students' comprehensive knowledge on the subject. At the same time, students can also trade in confusion on the problem back to the teacher, enabling interactive communication on the network. Teachers can issue the students through this system centralized processing, classification analysis through transaction records, easier to find the problem. 


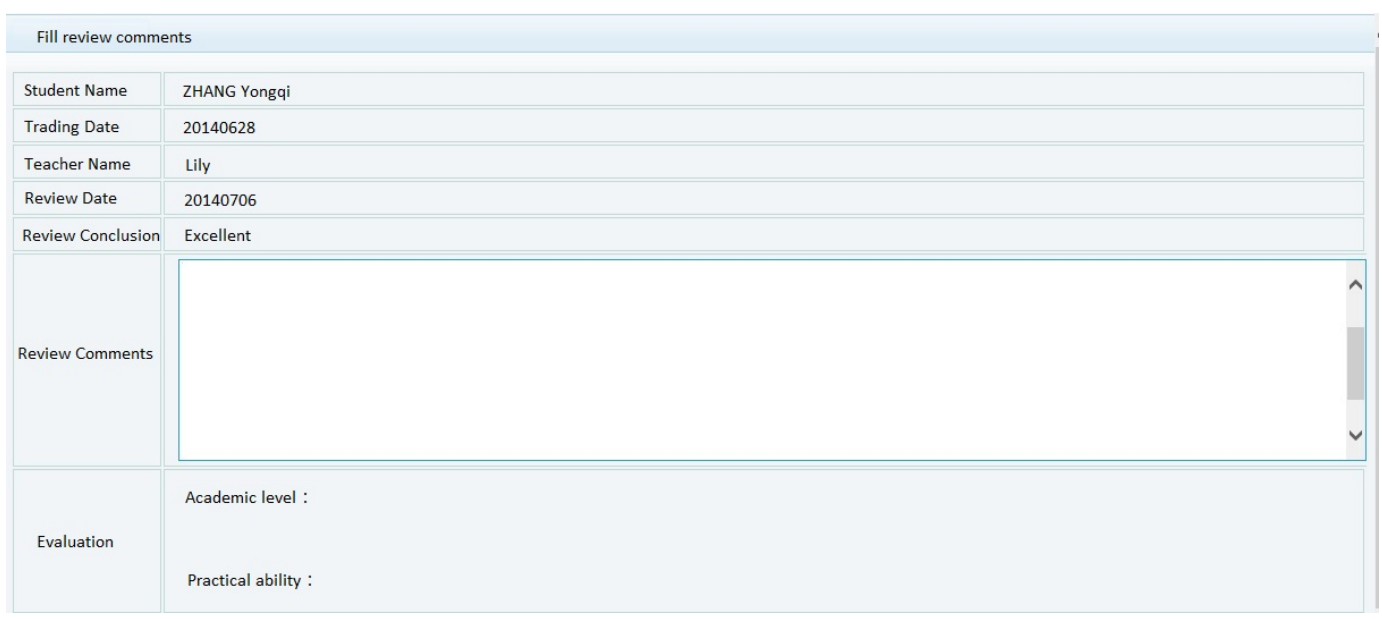

Fig.4. Evaluation function interface

\section{Conclusion}

Build e-commerce teaching simulation trading system requires a combination of knowledge and skills of students from the School of Economics and Management School of Information Science and Technology of the reserves will be organically fundamental analysis, technical analysis and practice together, either to consolidate the theoretical knowledge of students they can exercise practical ability of college students. Students build a new trading system to fully cater to simulate zero-based college students to learn and apply knowledge of e-commerce, this approach is more able to help students master the inherent principle of virtual trading system and operational mechanism for the accumulation of capital markets in the future to participate in valuable real experience.

\section{Acknowledgments}

This work was partly supported by the research project of Liaoning Institute of Mechatronic Technology. "Scheme to improve the practical ability of e-commerce Majors"(JYLX2012049) and " Exploration and research of construction of soft environment in training base "(JYLX2013026).

\section{References}

[1] JIAO J.X, Helander M.G. Development of an electronic configure-to-order platform for customized product development[J]. Computers in Industry. 2006, 57 (3):231- 244.

[2] Panagiotis V, Ioannis G. Karafyllidis. Simulation of quantum key expansion using quantum cellular automata[J]. Computer Physics Communications. 2009, 180(2): 251-255.

[3] HAN X.M. The application of web technology in electronic commerce[C]. 2009 International Conference on Computer Technology and Development. Kota Kinabalu, Malaysia.2009: 636-640.

[4] LIN C, PENG X.H. Research on network architecture with trustworthiness and controllability[J]. Journal of Computer Science and Technology.2006, 21(5): 732-739.

[5] RAO Y, FENG B.Q. Web service-oriented dynamic E-Business integration framework[J]. Computer Integrated Manufacturing Systems.2004, 10(11): 1454-1458. 